\title{
Clarification of Characteristics of Character Strengths Utilized in Stressful Situation
}

\author{
Shogo Matsumoto, Koichiro Aoki, Shogo Komatsu, Chieko Kato \\ Graduate School of Information Sciences and Arts, Toyo University, Saitama, Japan \\ Email: s3b101900080@toyo.jp
}

How to cite this paper: Matsumoto, S., Aoki, K., Komatsu, S., \& Kato, C. (2021). Clarification of Characteristics of Character Strengths Utilized in Stressful Situation. Open Journal of Social Sciences, 9, 157-166. https://doi.org/10.4236/jss.2021.92011

Received: January 6, 2021

Accepted: February 7, 2021

Published: February 10, 2021

Copyright (c) 2021 by author(s) and Scientific Research Publishing Inc. This work is licensed under the Creative Commons Attribution International License (CC BY 4.0).

http://creativecommons.org/licenses/by/4.0/

\begin{abstract}
The research of positive psychology has been applied on various fields such as education and industry as therapies and activities (positive psychology intervention) to enhance positive emotions, behavior, and recognition. Among various interventions, understanding one's strengths and exercises to utilize the strengths in daily life has been proved effective. Previous studies about strengths indicated that the character strengths are utilized for overcoming adversity. There is a possibility that proper choice and utilization of character strengths depending on situations and stressors lead to overcoming stressful situations. This study conducted a survey on students' own strengths and strengths used in stressful situations for identification of character strengths which are useful for stress coping. The purpose of this study is to clarify how to utilize the strengths in stressful situations by analyzing free-description obtained from the survey. The results of the survey on the students' own strengths and strengths used in stressful situations showed the characteristics of each strength. In particular, the analysis on the free-description about the strengths regarding "Transcendence" clarified in detail the way to utilize the strength "Hope" in stressful situations. This study brought knowledge about positive psychology interventions such as utilization of "Hope" in daily life as stress coping.
\end{abstract}

\section{Keywords}

Positive Psychology, Character Strength, Stress Coping, Questionnaire, Text Mining

\section{Introduction}

Conventionally, psychology has been focusing on solving people's psychological issues through understanding, treating, and preventing mental illnesses. In re- 
cent years, positive psychology has been attracting more public attention as a study to realize a better way of life focusing on the positive aspects in a human's mind such as happiness, optimism, and strengths. Positive psychology is posited by Seligman M., the former president of the American Psychological Association. Research field of positive psychology is classified as positive subjective experiences (happiness, satisfaction, etc.), personality (strengths, values, etc.), and systems (family system, workplace system, community, etc.). For instance, the sense of happiness is one of the most controversial topics in psychology while it is usually measured as "subjective well-being" that includes "life satisfaction" and "emotions" in the field of positive psychology. Identifying personalities, the predictors of well-being, is also one of the major movements in positive psychology. Previous studies have shown the relationship between happiness and personal features such as trust, patience, self-esteem, and extroversion. Because some of these personal features can be acquired, psychological intervention is expected to promote acquisition of these features and enhance happiness.

The research of positive psychology has been applied on various fields such as education and industry as therapies and activities (positive psychology intervention) to enhance positive emotions, behavior, and recognition. Typical interventions include "gratitude exercise" to give thanks to others, and "three good things exercise" to remind participants of three good things that happened on that day. In a study conducted by Seligman et al. (2005) and his team, participants who continued to practice the "three good things exercise" for a week showed more happiness and less depression, and the effect lasted for six months. Besides, understanding one's strengths and exercises to utilize the strengths in daily life has also been proved effective.

In positive psychology, "strength" is defined as the "characteristic which enables a person to play an active role and do the best" (Wood et al., 2011), which includes individual, physical, and psychological strengths. "Character strength" has attracted attention as a measurement scale focusing on strengths and understanding individual strengths in positive personality as reflected in thoughts, emotions, and behaviors (Park et al., 2004).

Peterson \& Seligman's (2004) VIA-IS (Values in action inventory of strength) is a typical scale in the measurement of personal strength. It measures 24 strengths (Table 1) identified as the research outcomes. As shown in Table 1, VIA-IS classifies 24 strengths into six virtues. In addition to the virtue classification, there are also attempts to identify the factor structure of personal strengths by focusing on the details of these strengths (e.g., Peterson, 2006; Peterson et al., 2008; Brdar \& Kashdan, 2010). In Harzer \& Ruch's (2015) study, a five-factor structure was adopted based on previous studies, which are emotional strengths, interpersonal strengths, strengths of restraint, intellectual strengths, and theological strengths (Table 2). Among the 24 strengths, those with the highest VIA-IS scores are called "signature strengths (SS)" as they characterize individuals and bring elation. 
Table 1. Twenty-four strengths and six virtues in VIA-IS.

\begin{tabular}{cc}
\hline Virtue & Strength \\
\hline Wisdom & Creativity, Curiosity, Judgement, Love of learning, Perspective \\
Courage & Bravery, Persistence, Honesty, Zest \\
Humanity & Capacity to love and be loved, Kindness, Social intelligence \\
Justice & Teamwork, Leadership, Fairness \\
Moderation & Self-control, Prudence, Modesty, Forgiveness \\
Transcendence & Appreciation of beauty and excellence, Religiousness and \\
spirituality, Hope, Gratitude, Humor
\end{tabular}

Table 2. Five-factor structure of character strengths.

\begin{tabular}{cc}
\hline Factor & Strength \\
\hline Emotional strengths & $\begin{array}{c}\text { Bravery, Zest, Hope, Honesty, Perspective } \\
\text { Capacity to love and be loved, Kindness, Leadership, } \\
\text { Teamwork, Humor }\end{array}$ \\
Interpersonal strengths & $\begin{array}{c}\text { Prudence, Forgiveness, Fairness, Modesty } \\
\text { Creativity, Curiosity, Love of learning } \\
\text { Intellectual strengths } \\
\text { Theological strengths }\end{array}$ \\
Appreciation of beauty and excellence, Gratitude, \\
Religiousness and spirituality
\end{tabular}

Interventions regarding strengths sometimes ask participants to focus on and utilize their own SS in daily life. For instance, people whose SS is "Love of learning" among "Wisdom" can utilize their strength for researching about topics of interest. The intervention study focusing on SS (Seligman et al., 2005) reported that participants who utilized their SS in the above way improve happiness and depression during six months. In contrast, participants who only identified their SS did not show such long-term improvement. Understanding one's own strengths and learning how to utilize them in daily life is considered to contribute to improvement of lasting happiness.

Previous studies about strengths indicated that the character strengths are utilized for overcoming adversity such as dealing with trauma (Peterson \& Seligman, 2003; Peterson et al., 2008) and recovery from illness (Peterson et al., 2006). The study by Harzer \& Ruch (2015) examined relationships between character strengths, coping, work-related stress, and job satisfaction and showed that intellectual, emotional, and interpersonal strengths were related to coping. In addition, intellectual strengths partially mediated and buffered a negative effect of work-related stress on job satisfaction. There is a possibility that proper 
choice and utilization of character strengths depending on situations and stressors lead to overcoming stressful situations.

This study conducted a survey on students' own strengths and strengths used in stressful situations for identification of character strengths which are useful for stress coping. The purpose of this study is to clarify how to utilize the strengths in stressful situations by analyzing free-description obtained from the survey.

\section{Method}

\subsection{Survey Date and Participants}

A survey was conducted for fifty-six undergraduates in their teens and twenties and five graduate students in their twenties and thirties of A and B-University in December 2020.

\subsection{Pocedure of Survey}

Questionnaires were conducted in classrooms of the universities. The participants were asked to answer the following questions (Table 3). in the form of free description after they took a class about twenty-four character strengths and six virtues (Table 1; Peterson \& Seligman, 2004) of the VIA-IS in positive psychology.

\subsection{Analysis Method}

Answers to question one or two in which more than two strengths were selected were removed from the following analysis. The number of valid answers was sixty-one. In addition, the strengths the participants selected for the questions were classified into the six virtues in accordance with Table 1. Proportions of the number of strengths classified into each virtue were compared between the two questions by means of chi-squared test and residual analysis.

Based on the above analysis, text mining was conducted on the free-description obtained from the questionnaires. The software "KH Coder (Higuchi, 2016; 2017)" was used for the text mining. After morphological analysis was conducted as preprocessing for text data, co-occurrence net-work and self-organizing maps were performed. The characteristics of the strengths used in stressful situations were discussed based on the co-occurrence network images and the self-organizing maps made by the following methods.

Table 3. Five factor structure of character strengths.

Question one (One's own strength): What is your "character strength" among the following strengths (Table 1)? Please write about in what situation this strength was used.

Question two (Strength used in stressful situations): What do you think is the strength used when you feel stress among the following strengths (Table 1)? Please write about the reason why you think so. 


\subsubsection{Co-Occurrence Network Analysis}

Co-occurrence network analysis is a method for representing co-occurrence relationships between words. In co-occurrence network image, words which are similar in their occurrence pattern are linked to each other among extracted words from text data. More frequent words are expressed by larger circles and stronger co-occurrence relationships are expressed by bold lines. In addition, words which belong to the same cluster are expressed by the same color as a result of clustering based on the occurrence pattern of the words.

\subsubsection{Self-Organizing Maps}

Self-organizing maps (SOM) is one of artificial neural networks and this method maps input data to optional dimensions by means of unsupervised learning. In this study, two-dimensional maps composed of hexagonal lattices (neuron) were made as a result of SOM. Each word was placed in any neuron and words whose occurrence patterns were similar were located in neurons nearby. In addition, a result of clustering based on characteristics of each neuron was expressed by different colors.

\section{Results}

\subsection{Results of Questionnaire}

As a result of the survey, the most selected strengths as one's own strength were those regarding "Courage (36.1\%)" and twenty-two participants selected them. Among the twenty-two participants, sixteen selected "Persistence", five selected "Zest", and one selected "Honesty". In contrast, the most selected strengths as strength used in stressful situations were those regarding "Transcendence (44.3\%)" and twenty-seven participants selected them. Among the twenty-seven participants, twenty selected "hope", four selected "humor", two selected "Spirituality", and one selected "Gratitude".

The result of chi-squared test showed that there was a significant difference in the proportions of the number of strengths classified into six virtues between the question one and two $(p<0.01)$. As a result of residual analysis, the proportions of strengths regarding "Courage $(p<0.01)$ " and "Justice $(p<0.01)$ " were significantly higher in question one than question two. The proportion of strengths regarding "Transcendence $(p<0.01)$ " was significantly higher in question two than question one.

The above results indicated that the participants mainly selected the strength regarding "Transcendence" as the strength used in stressful situations. Therefore, the text mining was conducted using free-description by the participants who selected the strengths regarding "Transcendence".

\subsection{Results of Text Mining}

As a result of text mining, a co-occurrence network image and a self-organizing map were shown in Figure 1, Figure 2 and Japanese-English translation for these figures was shown in Table 4. 
S. Matsumoto et al.

Table 4. Japanese-English Translation for Figure 1, Figure 2.

\begin{tabular}{|c|c|c|c|c|c|c|c|}
\hline Japanese & English & Japanese & English & Japanese & English & Japanese & English \\
\hline 悲観 & pessimism & 嫌う & hate & 悪い & bad & 嫌 & dislike \\
\hline 意識 & consciousness & 捉える & regard & イライラ & irritated & 自分 & myself \\
\hline 留まる & stay & 失敗 & failure & 志向 & oriented & 楽観 & optimism \\
\hline 行う & do & 方向 & direction & 希望 & hope & 感じる & feel \\
\hline 何事 & everything & ユーモア & humor & 未来 & future & 主義 & principle \\
\hline 原因 & factor & 気分 & mood & 出来る & can & 考える & think \\
\hline 解決 & solve & 信念 & belief & 役立つ & useful & ストレス & stress \\
\hline コントロール & control & 理由 & reason & 気持ち & feeling & 思う & guess \\
\hline マイナス & minus & 起きる & wake up & 兄 & older brother & 物事 & thing \\
\hline 継続 & continuation & 強み & strength & 忘れる & forget & 溜まる & collect \\
\hline 状況 & situation & 過去 & past & 今 & now & 少し & a little, a few \\
\hline 引きずる & dwell on & ネガティブ & negative & 顔 & face & 遊び心 & playfulness \\
\hline 解消 & eliminate & 多い & many & 感謝 & gratitude & & \\
\hline ポジティブ & positive & 抱える & have & 軽減 & reduction & & \\
\hline
\end{tabular}

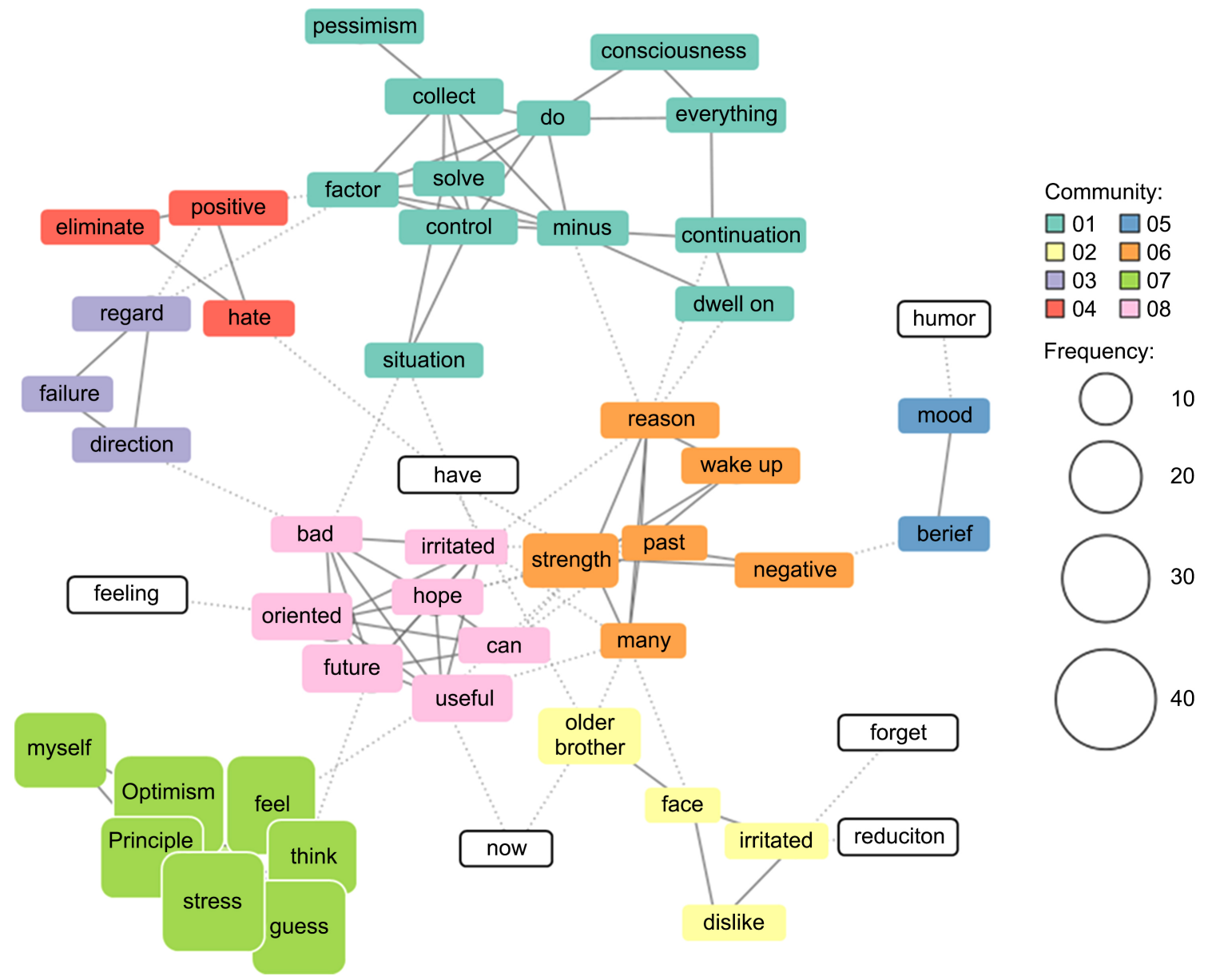

Figure 1. Result of co-occurrence network. 


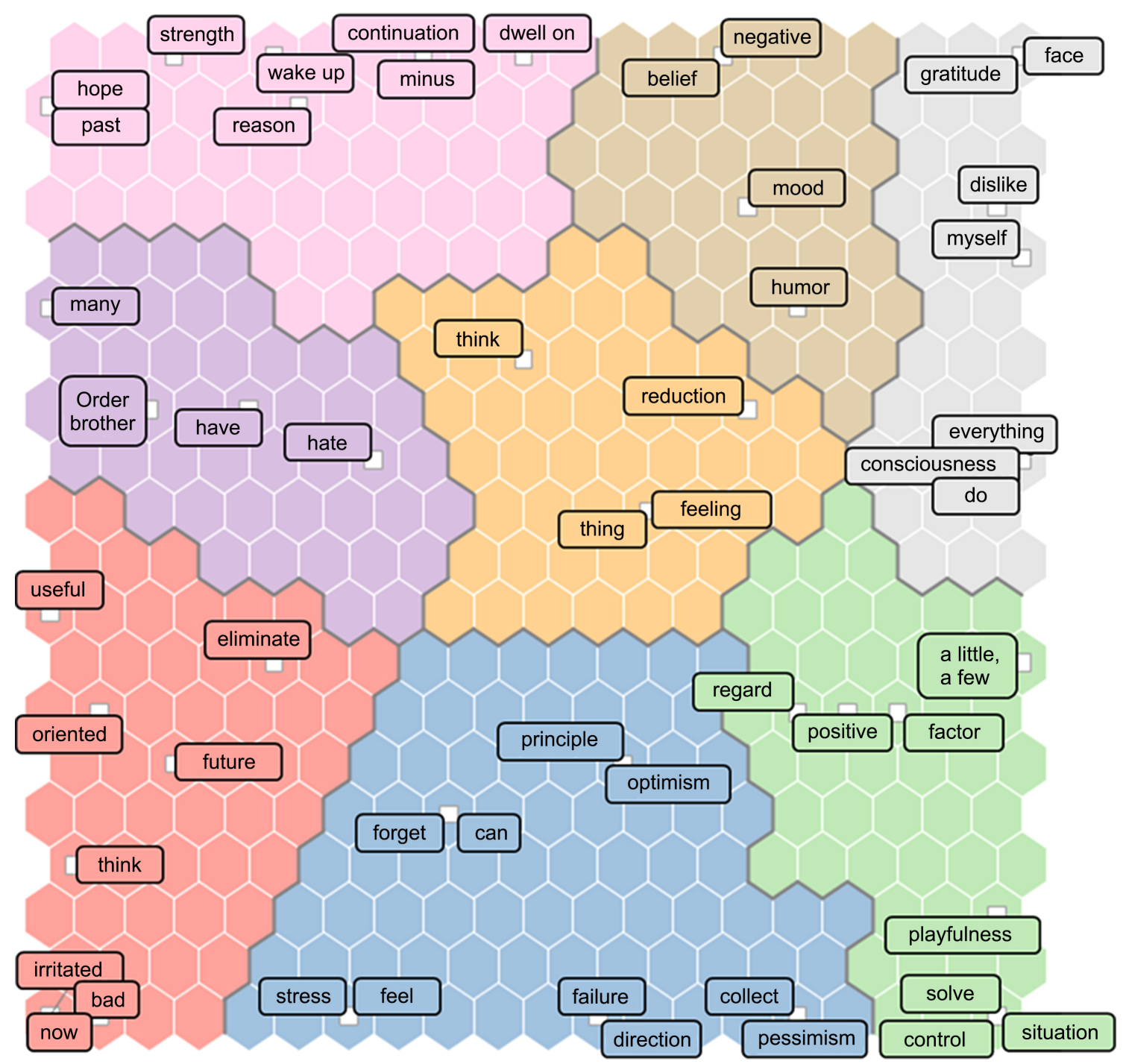

Figure 2. Result of SOM.

\section{Discussion}

\subsection{Discussion about Results of Questionnaire}

The most frequent strength mentioned by the university students is "Courage", particularly "Persistence". Ozaki and Ueno (2001) have investigated the impact of success and failure on university students in the present and future time, in which they found that successful experiences in the academic and sports aspects bring about internal changes such as "persistence and hard work". Such successful experiences can be interpreted as a process to demonstrate and improve personal strengths like persistence; and they are also touched on in this study as utilization of strengths.

The most frequently mentioned strength to cope with stress is "Transcendence", particularly "Hope". Saito and Okayasu (2011) examined in a study the effects of resilience factors on the stress process of university students, in which they revealed the effects of individual resilience, including "Positive evaluation" 
that emphasizes on the positive and optimistic aspects. According to the study, personal resilience can buffer the effects of daily life stressors on stress response that relates to oneself, interpersonal relationships, school life, and study. In addition, according to Izawa (2011), who studied the role of optimism in interpersonal stress process, students with high "Dispositional optimism" with positive expectations in the future are more capable in coping with stress; it is easier for them to cope with relationships positively (working on interpersonal relationships proactively and establishing better ones) and create resolutions (ignoring events to avoid problems). Furthermore, students who show an "Optimistic explanatory style" that attributes the causes of negative events to temporary specific factors tend to rank threats as low and coping with relationships negatively (give up and damage interpersonal relationships). They also show difficulties in creating resolutions. These previous studies suggest that demonstrating "Hope" in stress contributes to reduce stress, efficiently fight against them, and thus lower threat valuation. It is believed that target students in this study recalled previous stress process when looking back on their past experiences. Hence, the effectiveness of the above-mentioned strengths is demonstrated and reconfirmed then "Hope" as a strength related to optimism might, all in all, have been selected as the strength in stressful situations.

\subsection{Discussion about Results of Text Mining}

In the co-occurrence network diagram, words such as "optimism", "stress", "feel", and "think" formed a cluster at the bottom left of the diagram. In the self-organizing map, clusters of words such as "optimism", "stress", "failure", "pessimism", and "forget" were formed at the bottom of the figure. These clusters illustrate that optimism contributes to change pessimism, thoughts and feeling about stress, as well as to eliminate negative experiences such as failure. Similar to the previously mentioned study by Izawa (2011), the effect of optimism is demonstrated; it helps in threat evaluation and to cope with stress effectively.

In addition, words such as "hope", "future", and "annoyance" formed a cluster in the center of the co-occurrence network diagram. On the other hand, in the self-organizing map, words such as "hope", "past", "minus", and "hung up" formed a cluster in the upper left, and a cluster of words such as "future", "now", "annoyance", and "resolution" was formed in the lower left. These clusters visualize strengths such as hope and future orientation may help to get over past stress and cope with them through focusing on future hopes and confronting the problems. Kato and Snyder (2005) studied the validity and reliability of the dispositional Hope Scale, Japanese version, in which they revealed that there is a negative correlation between the dispositional hopes of target students and their stress response. Thus, focusing on positive events could change the overall feeling in the process when positive characteristics reduce stress response.

Considering the above, "Hope", which is the strength used in stressful situa- 
tions, can be divided as "optimism" related to evaluation of stress and "hope/ future-orientation" which promotes change of mind concerned with stress in the past and present. It can be said that each aspect of "Hope" contributes to dealing with stress in a different form.

\section{Conclusion}

The results of the survey on the students' own strengths and strengths used in stressful situations showed the characteristics of each strength. In particular, the analysis on the free-description about the strengths regarding "Transcendence" clarified in detail the way to utilize the strength "Hope" in stressful situations. This study brought knowledge about positive psychology interventions such as utilization of "Hope" in daily life as stress coping. There is room for verification of effects of "Hope" on stress response and coping. The positive psychology intervention for acquisition, improvement, and utilization of the strength "Hope" can be established by distinguishing similar concepts, "Hope", "Optimism", "Futurism" and clarifying their effects on the stress process.

Clarification of relationships between various psychological factors is desired in the future by quantitative surveys using psychological scales about character strengths and the stress process. For instance, Gander et al. (2012) conducted a survey on relationships between adult females' character strengths, work-related stress, and coping experiences and behaviors. The result of the survey showed that participants who had healthy work-related behavior and experience patterns differed in their strengths profiles from those that demonstrated unhealthy patterns. Especially the strengths of zest, persistence, hope, and curiosity seemed to play a key role in healthy and ambitious work behavior. In this way, different strengths can be used depending on target groups and environments. Expansion of participants and clarification of characteristics of strengths specific to each environment are expected for establishment of positive psychology intervention for dealing with various stress situations.

\section{Conflicts of Interest}

The authors declare no conflicts of interest regarding the publication of this paper.

\section{References}

Brdar, I., \& Kashdan, T. B. (2010). Character Strengths and Well-Being in Croatia: An Empirical Investigation of Structure and Correlates. Journal of Research in Personality, 44, 151-154. https://doi.org/10.1016/j.jrp.2009.12.001

Gander, F., Proyer, R. T., Ruch, W., \& Wyss, T. (2012). The Good Character at Work: An Initial Study on the Contribution of Character Strengths in Identifying Healthy and Unhealthy Work-Related Behavior and Experience Patterns. International Archives of Occupational and Environmental Health, 85, 895-904. https://doi.org/10.1007/s00420-012-0736-x

Harzer, C., \& Ruch, W. (2015). The Relationships of Character Strengths with Coping, 
Work-Related Stress, and Job Satisfaction. Frontiers in Psychology, 6, 165. https://doi.org/10.3389/fpsyg.2015.00165

Higuchi, K. (2016). A Two-Step Approach to Quantitative Content Analysis: KH Coder Tutorial Using Anne of Green Gables (Part I). Ritsumeikan Social Science Review, 52, 77-91. (In Japanese) http://www.ritsumei.ac.jp/file.jsp?id=325881

Higuchi, K. (2017). A Two-Step Approach to Quantitative Content Analysis: KH Coder Tutorial Using Anne of Green Gables (Part II). Ritsumeikan Social Science Review, 53, 137-147. (In Japanese) http://www.ritsumei.ac.jp/file.jsp?id=346128

Izawa, F. (2011). The Roles of Optimistic Explanatory Style and Dispositional Optimism in an Interpersonal Stress Process. The Japanese Journal of Personality, 19, 255-266. (In Japanese) https://doi.org/10.2132/personality.19.255

Kato, T., \& Snyder, C. R. (2005). The Relationship between Hope and Subjective Well-Being: Reliability and Validity of the Dispositional Hope Scale, Japanese Version: Reliability and Validity of the Dispositional Hope Scale, Japanese Version. The Japanese Journal of Psychology, 76, 227-234. (In Japanese) https://doi.org/10.4992/jipsy.76.227

Ozaki, H., \& Ueno, J. (2001). The Impact of Successful or Unsuccessful Past Experiences: Relationship with Present and Future. Bulletin of Graduate School of Human Sciences, Osaka University, 27, 63-87. (In Japanese)

Park, N., Peterson, C., \& Seligman, M. E. (2004). Strengths of Character and Well-Being. Journal of Social and Clinical Psychology, 23, 603-619. https://doi.org/10.1521/jscp.23.5.603.50748

Peterson, C. (2006). A Primer in Positive Psychology. Oxford: Oxford University Press.

Peterson, C., \& Seligman, M. E. (2004). Character Strengths and Virtues: A Handbook and Classification. Oxford: Oxford University Press.

Peterson, C., \& Seligman, M. E. P. (2003). Character Strengths before and after September 11. Psychological Science, 14, 381-384. https://doi.org/10.1111/1467-9280.24482

Peterson, C., Park, N., \& Seligman, M. E. P. (2006). Greater Strengths of Character and Recovery from Illness. The Journal of Positive Psychology, 1, 7-26. https://doi.org/10.1080/17439760500372739

Peterson, C., Park, N., Pole, N., D’Andrea, W., \& Seligman, M. E. P. (2008). Strengths of Character and Posttraumatic Growth. Journal of Traumatic Stress, 21, 214-217. https://doi.org/10.1002/jts.20332

Saito, K., \& Okayasu, T. (2011). Effect of Resilience on Stress Process and on Self-Esteem of University Students. The Japanese Journal of Health Psychology, 24, 33-41. (In Japanese) https://doi.org/10.11560/jahp.24.2 33

Seligman, M. E. P., Steen, T. A., Park, N., \& Peterson, C. (2005). Positive Psychology Progress: Empirical Validation of Interventions. American Psychologist, 60, 410-421. https://doi.org/10.1037/0003-066X.60.5.410

Wood, A. M., Linley, P. A., Maltby, J., Kashdan, T. B., \& Hurling, R. (2011). Using Personal and Psychological Strengths Leads to Increases in Well-Being over Time: A Longitudinal Study and the Development of the Strengths Use Questionnaire. Personality and Individual Differences, 50, 15-19. https://doi.org/10.1016/j.paid.2010.08.004 